\title{
Efficacy of Postoperative Concurrent Chemoradiation for Resectable Rectal Cancer: A Single Institute Experience
}

\author{
Joong Bae Ahn, M.D. ${ }^{1}$, Hee Chul Chung, M.D. ${ }^{5}$, Nae Choon Yoo, M.D. ${ }^{2,5}$, Jae Kyung Roh, M.D. ${ }^{2,5}$, Nam \\ Kyu Kim, M.D. ${ }^{3}$, Chang Ok Suh ${ }^{4}$, Gwi Eon $\mathrm{Kim}^{4}$, Jin Sil Seong ${ }^{4}$, Woong Ho Shim ${ }^{6}$, and Hyun Cheol \\ Chung, M.D. ${ }^{2,5}$ \\ ${ }^{1}$ Center for Colorectal Cancer, National Cancer Center, Departments of ${ }^{2}$ Internal Medicine, ${ }^{3}$ General Surgery and ${ }^{4}$ Radiation \\ Oncology, Yonsei University College of Medicine, ${ }^{5}$ Yonsei Cancer Center, ${ }^{6}$ Brain Korea 21 Project for Medical Science
}

\begin{abstract}
Purpose: For patients with Dukes' stage B and C rectal cancer, surgery followed by adjuvant chemoradiotherapy is considered to be the standard treatment. However, the drugs used in combination with 5 -fluorouracil $(5-F U)$, the method of administration, duration of adjuvant therapy and the frequencies of administration presently remain controversial topics. We investigated (1) the efficacy and safety of adjuvant radiotherapy and 5-FU/leucovorin (LV) chemotherapy for patients who had undergone curative resection and (2) the effect of dose related factors of 5-FU on survival.

Materials and Methods: 130 rectal cancer patients with Dukes' B or C stage disease who were treated with curative resection were evaluated. The adjuvant therapy consisted of two cycles of 5-FU/LV chemotherapy followed by pelvic radiotherapy with chemotherapy, and then $4 \sim 10$ more cycles of the same chemotherapy regimen were delivered based on the disease stage. The cumulative dose of 5-FU per body square meter (BSA), actual dose intensity and relative dose intensity were obtained. The patients were divided into two groups according to the median value of each factor, and the patients' survival
\end{abstract}

\section{INTRODUCTION}

The majority of rectal cancer patients will require surgical resection, but the cure rate has been less than $50 \%$ in these patients $(1,2)$. Because of anatomic characteristics, almost half of the recurrences of rectal cancer after surgery are located in the pelvis (3). To reduce the local failure, the role of radiation therapy has been emphasized. However, adjuvant radiotherapy alone has decreased local recurrences without any increased survival benefit $(4 \sim 6)$.

Correspondence: Hyun Cheol Chung, Yonsei Cancer Center, Yonsei University College of Medicine, 134 Sinchon-dong, Seodaemungu, CPO Box 8044, Seoul 120-752, Korea. (Tel) 82-2-361-7652, (Fax) 82-2-393-3652, (E-mail) unchung8@yumc.yonsei.ac.kr Received July 30, 2004, Accepted August 26, 2004 rates were compared.

Results: With a median follow-up duration of 52 months, the 5-year disease-free survival and overall survival rates of 130 patients were $57 \%$ and $73 \%$, respectively. Locoregional failure occurred in $17(13 \%)$ of the 130 patients, and the distant failure rate was $27 \%(35 / 130)$. The chemotherapy related morbidity was minimal, and there was no mortality for these patients. The cumulative dose of $5-\mathrm{FU} /$ BSA had a significant effect on the 5 -year overall survival for Dukes' $C$ rectal cancer patients $(p=0.03)$. Multivariate analysis demonstrated that only the performance status affected the 5 -year overall survival $(p=0.003)$.

Conclusion: An adjuvant therapy of radiotherapy and 5-FU/LV chemotherapy is effective and tolerable for Dukes' $B$ and $C$ rectal cancer patients. A prospective, multicenter, randomized study to evaluate the effects of the cumulative dose of 5-FU/BSA on survival is required. (Cancer $R e$ search and Treatment 2004;36:228-234)

Key Words: 5-fluorouracil, Dose intensity, Adjuvant chemotherapy, Rectal cancer,

Since the drug was first introduced in 1958, 5-fluorouracil (5-FU) has been a major component in chemotherapy for gastrointestinal tract cancer. 5-FU has been used for the treatment of metastatic or recurrent colon cancer, but the response rate (RR) has been only about $15 \sim 20 \%$ (7). Also, as a radiation sensitizer, 5-FU is known to improve the effectiveness of radiation therapy (8). In the 1980s, the biochemical modulation of 5-FU was actively studied, and leucovorin (LV) was shown to increase the activity of 5-FU by binding strongly to fluorodeoxyuridine monophosphate (FdUMP), which is a metabolite of 5-FU (9). The clinical phase I and II trials of combined therapy with 5-FU and LV demonstrated a $20 \sim 40 \%$ response rate as well as increasing the survival rate for colorectal cancer $(10,11)$. The 5-FU/LV regimen has now been accepted as the standard adjuvant therapy after curative resection in colon cancer. The National Cancer Institute Consensus Conference in 1990 stated that a combined modality therapy with 5-FU based chemotherapy was the standard 
postoperative adjuvant treatment for Dukes' $\mathrm{B}$ and $\mathrm{C}$ patients 12). However, the most effective combination of drugs, dosage, route and duration of therapy still needs to be decided.

In this study, we investigated the efficacy and safety of adjuvant radiotherapy and 5-FU/LV chemotherapy for Dukes' $\mathrm{B}$ and $\mathrm{C}$ rectal cancer patients who had undergone curative resection. The following findings were also obtained: 1) the total dose of 5-FU/ body surface area (BSA); and 2) the actual and relative dose intensity (ADI, RDI) of 5-FU. Finally, comparisons of survival rates according to these variables were analyzed.

\section{MATERIALS AND METHODS}

\section{1) Patients}

There were a total of 130 patients in our study that had histologically confirmed adenocarcinoma of the rectum. All these patients had undergone a potentially curative resection, and after which time, there was neither gross nor microscopical evidence of any residual disease. A tumor was considered as rectal cancer if a portion of the tumor was located below the peritoneal reflection or if the lower margin of the tumor was within $12 \mathrm{~cm}$ of the anal verge upon endoscopy examination. Patients were eligible for this study if a pathologic examination demonstrated that the tumor had penetrated the rectal wall and involved the perirectal fat or the adjacent organs by direct extension (Dukes' B), or if the tumor had metastasized to the regional lymph nodes (Dukes' C). Patients were excluded from the study if they had a history of malignancy within the previous 5 years (except for a curatively treated cervix carcinoma-in-situ or a basal cell carcinoma of the skin), if they had previously received chemotherapy or radiotherapy of the pelvis, or if they had a severe coexisting disease. Pregnant or lactating women were also excluded from the study. Patients in the study were required to have an adequate performance status (an ECOG performance status of not more than 2) and normal hepatic, renal and bone marrow functions.

\section{2) Treatment schedule}

All the patients received two initial two cycles of chemotherapy that was followed by pelvic radiation therapy with concurrent chemotherapy. Four and ten more cycles of chemotherapy were then done for the patients with $\mathrm{B}$ and $\mathrm{C}$ disease, respectively. Adjuvant chemotherapy was initiated 2 3 weeks after the curative resection. The drug regimen consisted of intravenous boluses of $5-\mathrm{FU} 400 \mathrm{mg} / \mathrm{m}^{2} / \mathrm{d}$ and LV 20 $\mathrm{mg} / \mathrm{m}^{2} / \mathrm{d}$ on days 1 to 5 , and again on days 29 to 33 . During radiation therapy, boluses of $5-\mathrm{FU} 400 \mathrm{mg} / \mathrm{m}^{2} / \mathrm{d}$ and $\mathrm{LV} 20$ $\mathrm{mg} / \mathrm{m}^{2} / \mathrm{d}$ were concurrently administered for 3 days during weeks 1 and 5. After the radiation therapy, boluses of 5-FU $400 \mathrm{mg} / \mathrm{m}^{2} / \mathrm{d}$ and $\mathrm{LV} 20 \mathrm{mg} / \mathrm{m}^{2} / \mathrm{d}$ for 5 consecutive days were administered for four or ten more cycles. The chemotherapy was administered if the white blood cell count was $\geq$ $3.0 \times 10^{9} / \mathrm{L}$ and the platelet count was $\geq 100 \times 10^{9} / \mathrm{L}$. In those cases of incomplete hematologic recovery, the chemotherapy was delayed until the patient exhibited a full recovery, and then the 5-FU was administrated at $25 \%$ reduced doses during the subsequent cycles. When WHO grade III diarrhea or stomatitis developed, the 5-FU was administrated at $25 \%$ reduced doses in the subsequent cycles.

All the patients received pelvic radiation therapy with concurrent chemotherapy. Radiotherapy was delivered with a linear accelerator at a minimum energy of $4 \mathrm{MeV}$ through three fields (posterior to anterior and two laterals) to the primary tumor bed, the surrounding soft tissue, the internal iliac nodes and the presacral nodes. The large fields were treated with $180 \mathrm{cGy}$ per fraction for a total dose of 4,500 cGy in approximately a 5 week period. A total boost dose of $900 \mathrm{cGy}$ in three fractions was delivered to a reduced field that encompassed the tumor bed and the adjacent lymph nodes with a margin of $2 \mathrm{~cm}$.

\section{3) Follow up}

During the treatment, toxicities were evaluated to allow for an appropriate dose modification of the chemotherapy. All the patients underwent a physical examination, complete blood cell count and liver function tests before every course of chemotherapy. After treatment, the patients were subsequently evaluated every 6 months by physical examination, complete blood cell count, liver function tests, chest $\mathrm{x}$-ray, serum CEA and abdomino-pelvic CT or MRI. The median follow-up duration was 52 months (the range was 27 to 95 months).

\section{4) Statistical analysis}

The overall survival duration was calculated from the date of surgery until the date of death. The disease free survival duration was calculated from the date of surgery until the date of recurrence or to the date of death from any cause. The Survival curves were calculated using the Kaplan-Meier method and comparisons of survival were done with the log-rank test. Chi-square tests and t-tests were used to compare the difference of variables between the two groups that had been divided by reference to the median cumulative dose of 5-FU/BSA. Multivariate regression analysis was employed to find the most significant prognostic factors. $\mathrm{T}$ tests were used to compare dose-related factors according to the primary failure site.

\section{RESULTS}

\section{1) Patient characteristics}

Demographic data and other characteristics of the patient population are summarized in Table 1. Overall, there was essentially equal distribution of gender, age, ECOG performance status, differentiation, and preoperative CEA level distributions between the two groups based on the cumulative dose of 5-FU. There were 70 men and 60 women with a median age of 54 years (the range was 22 to 78 years). 124 patients $(95 \%)$ had an ECOG performance status of $0 \sim 1$. Eight-one cases (62\%) had nodal metastasis (stage C). The preoperative CEA level was more than $5 \mathrm{ng} / \mathrm{ml}$ in 46 cases (37\%). Most of the patients had tumors that were either well or moderately differentiated. The median number of cycles of chemotherapy was 6 cycles for Dukes' B and 10 cycles for Dukes' C stage. The chemotherapy was stopped early in 9 patients due to tumor recurrence. Of these patients, 2 had Dukes' $\mathrm{B}$ disease and 7 had Dukes' $\mathrm{C}$ disease. 
Table 1. Patient characteristics

\begin{tabular}{|c|c|c|c|c|}
\hline & \multicolumn{2}{|c|}{ Cumulative dose of 5-FU } & \multirow{2}{*}{$\mathrm{p}$ value } & \multirow{2}{*}{ Total } \\
\hline & $\begin{array}{l}\text { Below the } \\
\text { median }\end{array}$ & $\begin{array}{l}\text { Above the } \\
\text { median }\end{array}$ & & \\
\hline No. of patients & 66 & 64 & & 130 \\
\hline $\operatorname{Sex}(M: F)$ & $36: 30$ & $34: 30$ & 0.871 & $70: 60$ \\
\hline Age & & & & 0.900 \\
\hline Median (range) & $\begin{array}{c}54 \\
(22 \sim 78)\end{array}$ & $\begin{array}{c}54 \\
(30 \sim 74)\end{array}$ & & $\begin{array}{c}54 \\
(22 \sim 78)\end{array}$ \\
\hline Performance status & & & 0.241 & \\
\hline 0 & 2 & 3 & & 5 \\
\hline 1 & 59 & 60 & & 119 \\
\hline 2 & 5 & 1 & & 6 \\
\hline Differentiation & & & 0.198 & \\
\hline Well & 7 & 13 & & 20 \\
\hline Moderately & 47 & 46 & & 93 \\
\hline Poorly & 5 & 2 & & 7 \\
\hline Mucinous & 7 & 3 & & 10 \\
\hline Preop. CEA (ng/ml) & & & 0.530 & \\
\hline$<5$ & 38 & 39 & & 77 \\
\hline$\geq 5$ & 23 & 23 & & 46 \\
\hline Dukes' stage & & & 0.964 & \\
\hline B & 25 & 24 & & 49 \\
\hline $\mathrm{C}$ & 41 & 40 & & 81 \\
\hline Cycles in Dukes' B & & & 0.009 & \\
\hline Median (range) & $\begin{array}{c}6 \\
(2 \sim 6)\end{array}$ & $\begin{array}{c}6 \\
(6 \sim 11)\end{array}$ & & $\begin{array}{c}6 \\
(2 \sim 11)\end{array}$ \\
\hline Cycles in Dukes' C & & & 0.000 & \\
\hline Median (range) & $\begin{array}{c}7 \\
(2 \sim 12)\end{array}$ & $\begin{array}{c}12 \\
(8 \sim 13)\end{array}$ & & $\begin{array}{c}10 \\
(2 \sim 13)\end{array}$ \\
\hline
\end{tabular}

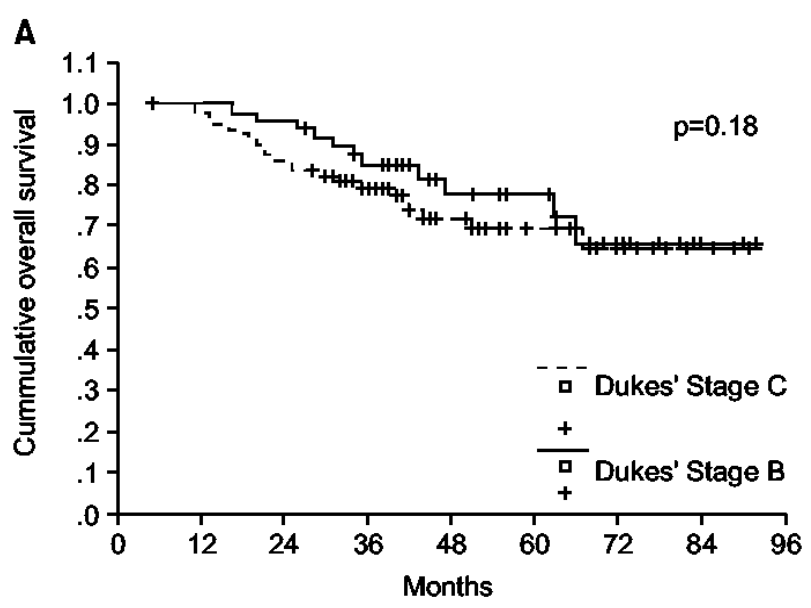

2) Total administered dose of 5-FU/BSA, actual dose intensity (ADI) and relative dose intensity (RDI)

For Dukes' B patients, the median total dose of 5-FU/BSA was $12.1 \mathrm{~g} / \mathrm{m}^{2}$ (range, $2.0 \sim 23.5 \mathrm{~g} / \mathrm{m}^{2}$ ), and it was $18.1 \mathrm{~g} / \mathrm{m}^{2}$ (range, 3.2 26.4 g/m²) for Dukes' C. For Dukes' B patients, the median ADI was $462 \mathrm{mg} / \mathrm{m}^{2} /$ week (range, $334 \sim 500 \mathrm{mg} /$ $\mathrm{m}^{2} /$ week), and it was $431 \mathrm{mg} / \mathrm{m}^{2} /$ week (range, $247 \sim 500 \mathrm{mg} /$ $\mathrm{m}^{2} /$ week) for Dukes' C. The median RDI was 92 (range, 60 100) for Dukes' B patients and it was 86 (range, 49 100) for Dukes' C patients.

\section{3) Survival}

The 5-year DFS and OS rate of all patients were $57 \%$ and $73 \%$, respectively. The 5-year DFS rate for Dukes' B patients was $64 \%$, while it was $51 \%$ for Dukes' C patients (Fig. 1A). The 5-year OS rate was $78 \%$ for Dukes' B patients, while it was $70 \%$ for Dukes' C patients (Fig. 1B).

A survival benefit for the 5-year OS and an increasing trend of survival in the 5-year DFS were found for the Dukes' $\mathrm{C}$ patients with an increased dose of 5-FU administered/BSA ( $p=0.03, p=0.07$, respectively) (Fig. $2 \mathrm{~A}, \mathrm{~B}$ ). However, there was no significant difference found for Dukes' $\mathrm{B}$ patients based on the administered dosage. There was no significant difference in survival with reference to the ADI or RDI.

\section{4) Recurrence}

Forty-nine of the 130 patients developed tumor recurrences with an overall recurrence rate of $38 \%$. Fifteen patients $(30 \%)$ with Dukes' B disease and 34 patients (42\%) with Dukes' C disease developed tumor recurrences. The recurrence pattern according to the initial recurrence site demonstrated 6 cases of local recurrence (12\%), 8 cases of abdominal recurrence (16\%), 32 cases of distant metastasis (65\%) and 3 cases $(6 \%)$ with both local and distant recurrence. In 18 cases, the initial site of distant metastasis was the liver, which was the most common site, and this was followed by the lung in 13 cases.

There was no difference for the dose-related factors according to the primary failure site (Table 2).

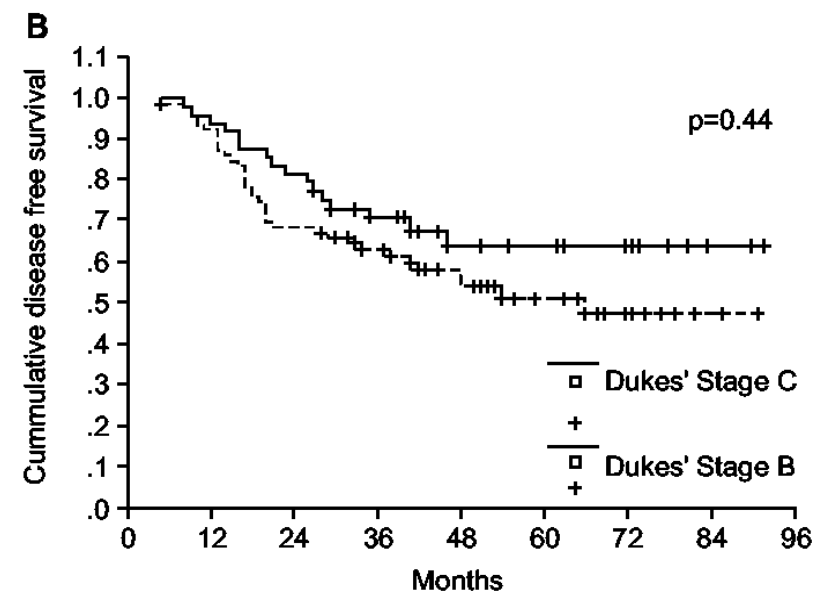

Fig 1. Survival for all patients according to the Dukes' stage (A) disease free survival, (B) overall survival. 
A

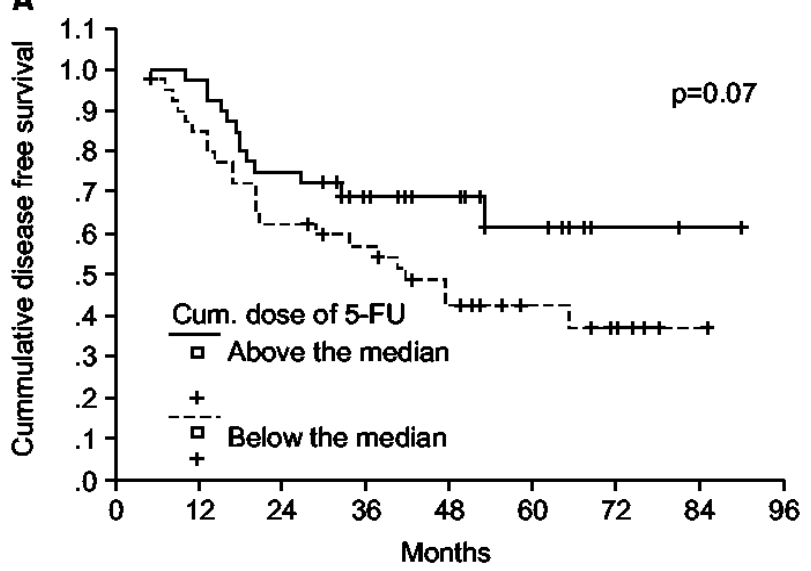

B

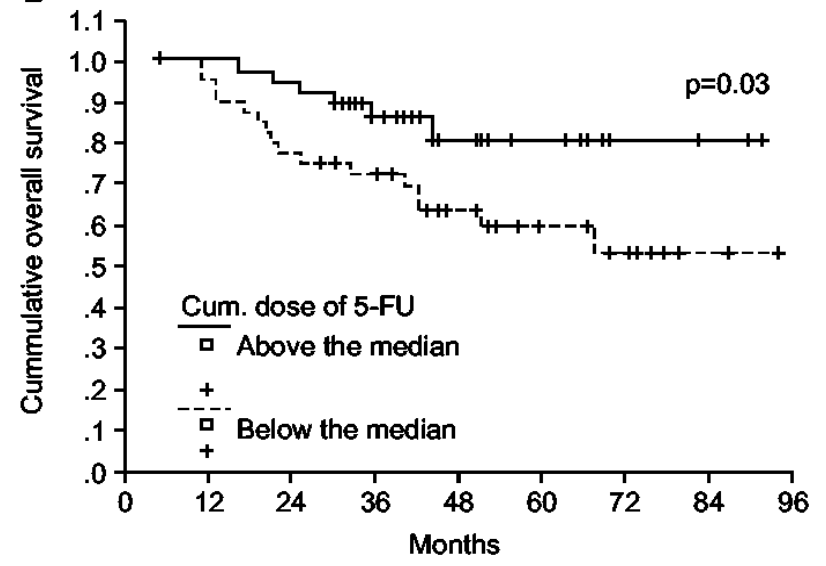

Fig. 2. Survival according to the cumulative dose of 5-FU in all Dukes' $\mathrm{C}$ patients (A) disease free survival, (B) overall survival.

Table 2. Comparison of dose-related factors according to the primary failure site

\begin{tabular}{lccc}
\hline & Loco-regional recurrence & Distant metastasis & p value \\
\hline Dukes' B & 4 & & 11 \\
No. of patients & $14.98 \pm 6.26$ & $13.21 \pm 3.91$ & 0.517 \\
Mean total dose of 5-FU & $0.49 \pm 0.14$ & $0.42 \pm 0.06$ & 0.193 \\
Mean actual dose intensity & $98.03 \pm 27.67$ & $84.74 \pm 11.33$ & 0.193 \\
Mean relative dose intensity & 10 & 24 & 0.458 \\
Dukes' C & $14.94 \pm 4.71$ & $16.49 \pm 5.77$ & 0.770 \\
No. of patients & $0.43 \pm 0.10$ & $0.44 \pm 0.08$ & 0.770 \\
Mean total dose of 5-FU & $86.43 \pm 19.28$ & $88.26 \pm 15.13$ & \\
Mean actual dose intensity & & \\
Mean relative dose intensity &
\end{tabular}

\section{5) Toxicity}

Among the total of 130 patients, grade 3 or 4 toxicities were observed in 55 patients $(42.3 \%)$. Grade 3 or 4 leukopenia developed in 15 patients (11.5\%). There was only one patient $(0.8 \%)$ who developed a grade 3 anemia, while there was no grade 3 thrombocytopenia. Forty-one patients (31.5\%) developed grade 3 or 4 diarrhea, and this was the most common non-hematologic toxicity. Seven patients (5.4\%) experienced grade 3 vomiting. Other severe toxicities rarely occurred: 5 patients $(3.8 \%)$ experienced grade 3 stomatitis.

\section{DISCUSSION}

Radical surgery has proven to be the most important treatment modality in rectal cancer. Although radical surgery is possible in locally advanced rectal cancer, the cure rate hasn't reach $50 \%$ due to high local recurrence rate, which is unlike colon cancer.

Even if the proximal and distal margins of the tumor are correctly excised, the risk of local recurrence is high as the lateral, posterior and anterior borders are minute. The local recurrence was reduced in many studies that focused on the effects of radiation therapy, but an improved survival rate was not achieved due to a high rate of systemic recurrence (13 16). In order to reduce the systemic failure, beginning the early 1980 's, a combined modality treatment of adjunctive chemotherapy and radiation therapy has been tried out. A randomized study was carried out by the NSABP in 1977 for comparing a control group that received surgery alone, a group that received radiation therapy after surgery and a group that received chemotherapy after surgery. For the group that received chemotherapy as compared to the group of surgery alone, the 5 -year disease free survival rate $(42 \%$ vs. $30 \%$, respectively; $\mathrm{p}=0.006)$ and the overall survival rate (53\% vs. $43 \%$, respectively; $p=0.05$ ) were improved (5). Based on these results, it was suggested at the NIH consensus conference in 1990 that a combination of chemotherapy and radiation therapy after radical surgical resection be used as the standard treatment for Dukes' Stage B and C patients (12).

In our present study, the 5-year overall survival rate was $73 \%$. Although it is difficult to directly compare this result with those of existing studies, this is a much improved treatment result when comparing to the $53 \sim 59 \%$ of patients in the 
A

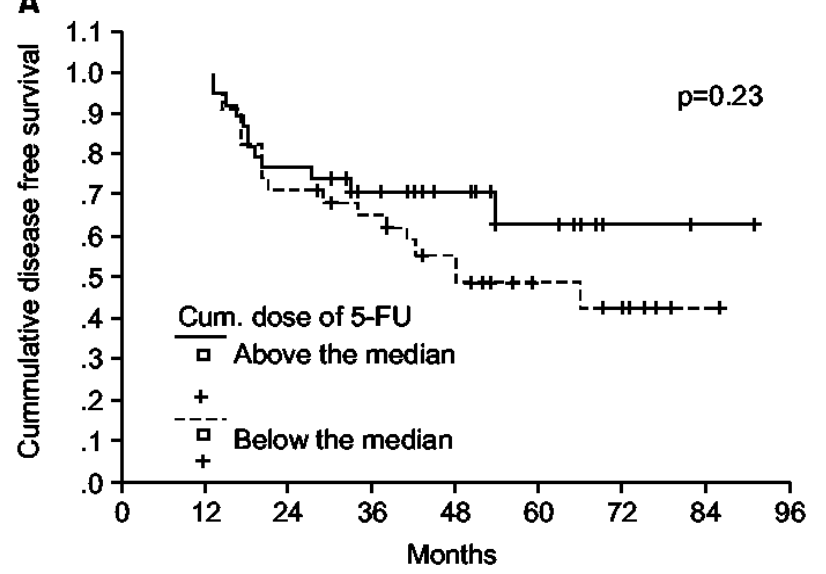

B

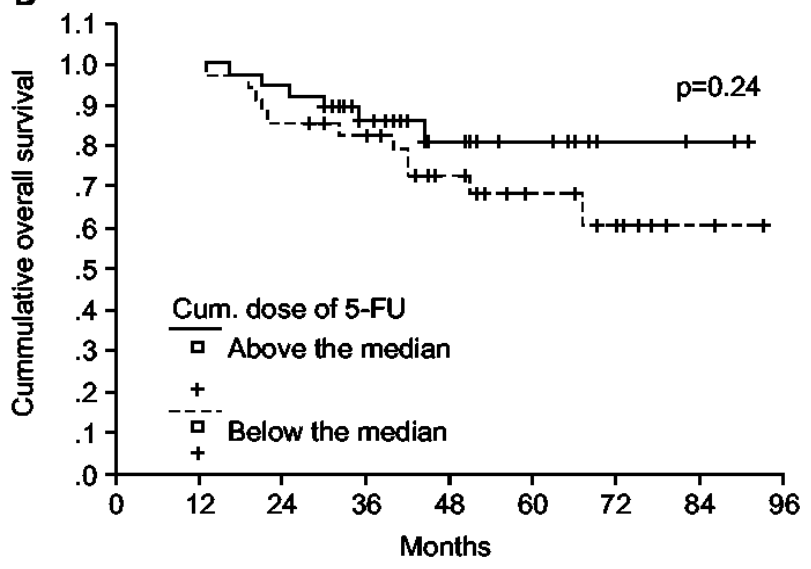

Fig. 3. Survival according to the cumulative dose of 5-FU for Dukes' C patients, except for the early (within 1 year) relapse (A) disease free survival (B) overall survival.

literature who received a combined therapy $(4,5,17)$. The disease free survival and overall survival rates were $57 \%$ and $73 \%$, respectively, which were results similar to the Mayo/ NCCTG continuous infusion group $(63 \%$ and $70 \%$, respectively) (18). The researchers of Intergroup 0144 pointed out that there was no difference in the DFS and OS between the continuous infusion group and bolus injection group, and they stated that central venous access was not needed in the bolus injection group (19). Based on these data, 5-FU continuous infusion and 5-FU/LV bolus injection both seem to be appropriate chemotherapy regimens as adjuvant chemotherapy for rectal cancer.

Combined chemoradiotherapy based on 5-FU after surgery is recognized as the standard therapy for rectal cancer. However there is no standard guideline for the combination and duration of the specific agents to be used. In many studies, 2 cycles of chemotherapy were administered before radiation therapy regardless of the Dukes' stage (20). In the present study, survival rates according to dose intensity and cumulative dose of 5-FU were analyzed to find out the effects of the dose-related factors of 5-FU on survival. The survival according to the cumulative dose of 5-FU/BSA was analyzed at each stage. The median cumulative dose of 5-FU/BSA was $12.1 \mathrm{~g} / \mathrm{m}^{2}$ for Dukes' B, while it was $18.1 \mathrm{~g} / \mathrm{m}^{2}$ for Dukes' C. For Dukes' B patients, there were no differences for the 5-year DFS and OS rates between the group that received more than the median dose (64\% and $78 \%$ ) and the group that received less than the median dose $(61 \%$ and $77 \%)$ ( $p=0.67$ for DFS, $p=0.63$ for OS). For Dukes' C patients, the 5-year DFS and OS rates were improved for the group that received more than the median dose $(61 \%$ and $81 \%)$ than for the group that received less than the median dose $(43 \%$ and $60 \%)(p=0.07$ for DFS, $p=0.03$ for OS) (Fig. 2A, B). As those cases of treatment discontinuation during treatment due to relapse may have confounded the results of the dose-relationships, we reanalyzed our patients by excluding the patients whose disease recurred within 1 year after surgery. For the Dukes' B patients, once again, there was no difference noted in the 5-year DFS and OS between the group that received more than the median dose $(66 \%$ and $80 \%)$ and the group that received less than the median dose $(66 \%$ and $81 \%) \quad(p=0.44$ for DFS, $p=0.75$ for OS $)$ In contrast, for the Dukes' $\mathrm{C}$ patients, there was a tendency towards improved 5 -year DFS and OS rates in the group that received more than the median dose $(63 \%$ and $81 \%)$ than for the group that received less than the median dose $(49 \%$ and $68 \%)(p=0.23$ for DFS, $\mathrm{p}=0.24$ for OS). Unlike the Dukes' B patients, there was a gradual disparity of the survival curves with the follow up duration between the two Dukes' C groups (Fig. 3A, B). When the data was analyzed with reference to the dose intensity, there was no difference in the 5 year DFS and the OS between the two groups. These results indicate that the cumulative dose of 5-FU as compared to the dose intensity was a more important prognostic factor.

Tumor recurrence occurred in 49 patients in the present study, with a recurrence rate of $38 \%$. This was similar to the recurrence rate of $33 \sim 42 \%$ reported in studies in which chemoradiotherapy was administered, but it was superior to the recurrence rate of $55 \sim 63 \%$ in which only surgery was performed. As the first site of recurrence, 17 patients developed a local recurrence with a recurrence rate of $13 \%$, and 35 patients developed distant metastasis with a recurrence rate of $27 \%$. These results were similar to the previous studies in which chemoradiotherapy was administered, but our results were superior to those studies in which surgery alone was performed $(4,5)$

The prognostic factors in rectal cancer include pathologic stage, preoperative CEA level, differentiation, venous invasion and performance status (21). In the present study, the comparison of the 5-year DFS and OS rates according to age, gender, pre-treatment performance status, pathologic stage, type of surgery, pre-treatment CEA level, cumulative dose of 5-FU/ BSA, actual dose intensity and relative dose intensity of 5-FU were analyzed. The pre-treatment performance status was demonstrated to be the most important factor affecting the survival of patients (Table 3 ).

The most common non-hematologic toxicity of the 5-FU/LV chemotherapy used in the present study was diarrhea. About $31 \%$ of patients experienced diarrhea of more than grade 3 , and 
Table 3. Univariate and multivariate analysis of factors influencing disease-free survival and overall survival

\begin{tabular}{|c|c|c|c|c|c|c|}
\hline & 5 yr DFS $(\%)$ & p-value* & p-value ${ }^{\dagger}$ & 5 yr OS (\%) & p-value ${ }^{\ddagger}$ & p-value ${ }^{\S}$ \\
\hline Sex & & 0.43 & & & 0.11 & \\
\hline Male & 55.4 & & & 80.0 & & \\
\hline Female & 55.8 & & & 64.5 & & \\
\hline Age & & 0.22 & & & 0.36 & \\
\hline$<54$ & 63.7 & & & 74.8 & & \\
\hline$\geq 55$ & 46.6 & & & 70.4 & & \\
\hline EOCG & & 0.04 & 0.07 & & 0.0001 & 0.003 \\
\hline$\leq 1$ & 57.4 & & & 74.9 & & \\
\hline$\geq 2$ & 33.3 & & & 25.0 & & \\
\hline Stage & & 0.18 & & & 0.44 & \\
\hline $\mathrm{B}$ & 64.1 & & & 77.6 & & \\
\hline $\mathrm{C}$ & 51.3 & & & 69.7 & & \\
\hline Type of operation & & 0.40 & & & 0.29 & \\
\hline Miles' operation & 53.1 & & & 68.8 & & \\
\hline Lower Ant. Resection & 57.1 & & & 76.3 & & \\
\hline Differentiation & & 0.16 & & & 0.10 & \\
\hline Well & 82.5 & & & 82.4 & & \\
\hline Moderately & 51.5 & & & 74.0 & & \\
\hline Poorly and mucinous & 47.6 & & & 51.6 & & \\
\hline Preop CEA level (ng/ml) & & 0.57 & & & 0.39 & \\
\hline$\leq 5$ & 57.4 & & & 76.5 & & \\
\hline$>5$ & 54.0 & & & 65.3 & & \\
\hline 5-FU dose & & 0.10 & & & 0.15 & \\
\hline Below the median & 50.1 & & & 66.3 & & \\
\hline Above the median & 61.8 & & & 80.0 & & \\
\hline Actual dose intensity & & 0.56 & & & 0.80 & \\
\hline Below the median & 54.2 & & & 72.8 & & \\
\hline Above the median & 58.2 & & & 71.8 & & \\
\hline Relative dose intensity & & 0.56 & & & 0.80 & \\
\hline Below the median & 54.2 & & & 72.8 & & \\
\hline Above the median & 58.2 & & & 71.8 & & \\
\hline
\end{tabular}

${ }^{*}$ univariate analysis of 5 -year DFS within each factor, ${ }^{\dagger}$ multivariate analysis of 5 -year DFS among the factors, ${ }^{\dagger}$ univariate analysis of 5 -year OS within each factor, ${ }^{\S}$ multivariate analysis of 5 -year OS among the factors.

this was controlled by supportive care. The major hematologic side effect was leukopenia of more than grade 3, which occurred in $1.4 \%$ of patients during the entire chemotherapy cycle. Other chemotherapy toxicities were mostly grade 1 and 2 , and there was no treatment-related death.

\section{CONCLUSIONS}

The 5-year DFS and OS rates as a result of chemoradiotherapy with 5-FU/LV after curative resection for patients with Dukes' B and C rectal cancer were 57\% and 73\% respectively, and the recurrence rate was $38 \%$. It was also observed that for Dukes' $\mathrm{C}$ disease, the cumulative dose of 5-FU/BSA affected survival. Further prospective randomized studies are needed to find out the effect of the cumulative dose of 5-FU on patient survival.

\section{ACKNOWLEDGEMENT}

This study was supported by a grant of the Korea Health 21 R\&D Project, Ministry of Health \& Welfare, Republic of Korea (0405-BC01-0604-0002).

\section{REFERENCES}

1. Mohiuddin M, Marks G. Adjuvant radiation therapy of colon and rectal cancer. Semin in Oncol. 1991;8:411-420.

2. Pilipshen SJ, Heilweil M, Sternberg SH, Sternberg SS, Enker WE. Patterns of pelvic recurrence following definitive resections of rectal cancer. Cancer 1984;53:1354-1362.

3. Mendenhall MW, Million RR, Pfaff WW. Patterns of recurrence in adenocarcinoma of the rectum and rectosigmoid traeted with surgery alone: Implications in treatment planning with adjuvant radiation therapy. Int J Radiat Oncol Biol Phys 1983;9:977-985. 
4. Gastrointestinal Tumor Study Group. Prolongation of the disease-free interval in surgically resected rectal adenocarcinoma. N Engl J Med 1985;312:1465-1472.

5. Fisher B, Wolmark N, Rockette H, Redmond C, Deutsch M, WIchkerham DL, Fisher ER, Caplan R, Jones J, Lerner H, Gordon P, Feldman M, Cruz A, Legault-Poisson S, Welxler M, Lawrence W, Robidoux A. Postoperative adjuvant chemotherapy or radiation therapy for rectal cancer. J Natl Cancer Inst. 1988;80:21-29.

6. Gerard A, Buyse M, Nordlinger B, Loygue J, Pene F, Kempf P, Arnaud JP, Desaive C, Duez N. Preoperative radiotherapy as adjuvant treatment in rectal cancer. Final results of a randomized study of the European Organization for Research and Treatment of Cancer (EORTC). Ann Surg 1988;211: 606-614.

7. Higgins GA. Current status of adjuvant therapy in the treatment of large bowel tumor. Surg Clin North Am 1983;63:137-150.

8. Byfield JE, Calabro-Jones P, Klisak I. Pharmacologic requirements human tumor cells in vitro to combined 5-fluorouracil or ftorafur and X-rays. Int J Radiation Oncol Biol Phys 1982;8: 1923-1933.

9. Keyomarsi K, Moran RG. Folinic acid augmentation of the effects of fluoropyrimidines on murine and human leukemia cells. Cancer Res 1986;46:5229-5235.

10. Madajewicz S, Petrelli N, Rustum YM, Campbell J, Herrera L, Mittelman A, Perry A, Creaven PJ. Phase I-II trial of high dose calcium leucovorin and 5-fluorouracil in advanced colorectal cancer. Cancer Res 1984;44:4667-4669.

11. Machover D, Goldschmidt E, Chollet P, Metzger G, Zittoun J, Marguet J, Vandenbulcke JM, Misset JL, Schwarzenbergh L, Fourtillan JB, Gaget H, Mathe G. Treatment of advanced colorectal and gastric adenocarcinoma with 5-fluorouracil and high dose folinic acid. J Clin Oncol 1986;4:685-696.

12. NIH Consensus Conference. Adjuvant Therapy for Patients With Colon and Rectal Cancer. JAMA 1990;264:1444-1450.

13. Buyse M, Zeleniuch-Jacquotte A. Adjuvant therapy of colorectal cancr. Why we still don't know. JAMA 1988;259:3571-3578.
14. Moertel CG. Chemotherapy for colorectal cancer. N Engl J Med 1994;330:1136-1142.

15. Balslev IB, Pederson M. Postoperative radiotherapy in Dukes' $\mathrm{B}$ and $\mathrm{C}$ carcinoma of the rectum and rectosigmoid. Cancer 1986;58:22-28.

16. Yoo MR, Jang HS, Yoon SC, Chung SM, Kim YS, Kim SK, Kim IC, Shin KS. The Results of Postoperative Radiation Therapy in the Rectal Cancer. J Korean Cancer Assoc 1997; 29:111-116

17. Krook JE, Moertel CG, Gunderson LL. Effective Surgical Adjuvant Therapy for High-Risk Rectal Carcinoma. N Engl J MEd 1991;324:709-715.

18. O'Connell MJ, Martenson JA, Wieand HS, Krook JE, Macdonald JS, Haller DG, Mayer RJ, Gunderson LL, Rich TA. Improving adjuvant therapy for rectal cancer by combining protracted-infusion fluorouracil with radiation therapy after curative surgery. N Engl J Med 1994;331:501-507.

19. Smalley SR, Benedetti J, Williamson S, Robertson J, Fisher B, Martenson J, Benson AB, Robert M, Cripps C, MacDonald J. Intergroup 0144 - phase III trial of 5-FU based chemotherapy regimens plus radiotherapy (XRT) in postoperative adjuvant rectal cancer. Bolus 5-FU vs prolonged venous infusion (PVI) before and after XRT+PVI vs bolus 5-FU+ leucovorin $(\mathrm{LV})+$ levamisole $(\mathrm{LEV})$ before and after XRT+ bolus 5-FU+LV. Proc Am Soc Clin Oncol 2003;22:251 (abstr 1006).

20. Rodriguez-Bigas MA, Lin EH, Crane CH. Adenocarcinoma of the colon and rectum. In; Kufe DW, Pollock RE, Weichselbaum RR, Bast RC, Gansler TS, Holland JF, Frei E, eds. Cancer Medicine. Vol 2. 6th ed. Hamilton: BC Decker, 2003; 1635-1665.

21. Douglass HO Jr, Moertel CG, Mayer RJ, Thomas PR, Lindblad AS, Mittleman A, Stablein DM, Bruckner HW. Survival after postoperative combination treatment of rectal cancer. N Engl J Med 1986;315:1294-1295. 